\title{
Review Article \\ Recent Updates in the Treatment of Neurodegenerative Disorders Using Natural Compounds
}

\author{
Mahmood Rasool, ${ }^{1}$ Arif Malik, ${ }^{2}$ Muhammad Saeed Qureshi, ${ }^{3}$ Abdul Manan, \\ Peter Natesan Pushparaj, ${ }^{1}$ Muhammad Asif, ${ }^{4}$ Mahmood Husain Qazi, ${ }^{5}$ \\ Aamer Mahmood Qazi, ${ }^{6}$ Mohammad Amjad Kamal, ${ }^{7}$ \\ Siew Hua Gan, ${ }^{8}$ and Ishfaq Ahmed Sheikh ${ }^{7}$ \\ ${ }^{1}$ Center of Excellence in Genomic Medicine Research (CEGMR), King Abdulaziz University, Jeddah, Saudi Arabia \\ ${ }^{2}$ Institute of Molecular Biology and Biotechnology, (IMBB), The University of Lahore, Lahore 54000, Pakistan \\ ${ }^{3}$ Department of Biochemistry, Allama Iqbal Medical College, Lahore 54000, Pakistan \\ ${ }^{4}$ Department of Biotechnology and Informatics, BUITEMS, Quetta, Pakistan \\ ${ }^{5}$ Center for Research in Molecular Medicine (CRiMM), The University of Lahore, Lahore 54000, Pakistan \\ ${ }^{6}$ Ontario Institute for Cancer Research, MaRS Centre, Toronto, Canada \\ ${ }^{7}$ King Fahd Medical Research Center (KFMRC), King Abdulaziz University, Jeddah, P.O. Box 80216, Jeddah 21589, Saudi Arabia \\ ${ }^{8}$ Human Genome Centre, School of Medical Sciences, Universiti Sains Malaysia, Kubang Kerian, Kelantan, Malaysia
}

Correspondence should be addressed to Ishfaq Ahmed Sheikh; sheikhishfaq@gmail.com

Received 20 January 2014; Revised 23 March 2014; Accepted 24 March 2014; Published 23 April 2014

Academic Editor: Ibrahim Khalil

Copyright (C) 2014 Mahmood Rasool et al. This is an open access article distributed under the Creative Commons Attribution License, which permits unrestricted use, distribution, and reproduction in any medium, provided the original work is properly cited.

Neurodegenerative diseases are characterized by protein aggregates and inflammation as well as oxidative stress in the central nervous system (CNS). Multiple biological processes are linked to neurodegenerative diseases such as depletion or insufficient synthesis of neurotransmitters, oxidative stress, abnormal ubiquitination. Furthermore, damaging of blood brain barrier (BBB) in the CNS also leads to various CNS-related diseases. Even though synthetic drugs are used for the management of Alzheimer's disease, Parkinson's disease, autism, and many other chronic illnesses, they are not without side effects. The attentions of researchers have been inclined towards the phytochemicals, many of which have minimal side effects. Phytochemicals are promising therapeutic agents because many phytochemicals have anti-inflammatory, antioxidative as well as anticholinesterase activities. Various drugs of either synthetic or natural origin applied in the treatment of brain disorders need to cross the BBB before they can be used. This paper covers various researches related to phytochemicals used in the management of neurodegenerative disorders.

\section{Introduction}

Various neurodegenerative (progressive loss of structure and/or function of neurons) disorders share many common features at both cellular and subcellular levels. Intracellular and extracellular changes could be observed in Alzheimer's, Parkinson's, Huntington's, and other neurodegenerative diseases. As far as cellular and subcellular biological events are concerned, the cytosol and endoplasmic reticulum are responsible for the synthesis of new structural and functional protein molecules. Mechanisms of translational as well as posttranslational modifications are highly complex and sophisticated in nature. Any polypeptide that fails to fold properly is directed to its degradation processes or known as autophagy and ubiquitin proteasome system $[1,2]$.

Neurodegenerative disorders are usually characterized by accumulation of abnormal protein aggregation that leads to inflammation as well as oxidative stress in the central nervous 
system (CNS). Parkinson's disease (PD) and Alzheimer's disease (AD) are the most common disorders of nervous system caused by environmental and genetic influences [35]. It has been observed that various types of biological mechanisms are associated with neurodegenerative disorders such as oxidative stress, aggregates of proteins in neurons, depletion or in sufficient synthesis of neurotransmitters, degradation of neurotransmitters in the synaptic cleft due to the higher activity of enzymes, abnormal ubiquitination, mitochondrial dysfunction, and excitotoxicity of neurons as well as disarrangement or damage of the blood brain barrier (BBB) (Figure 1).

$\mathrm{AD}$ is characterized by cognitive decline, neuronal loss, neuronal inflammation, and neuronal death, which is also known as apoptosis and/or necroptosis. Moreover, aggregation of $\beta$-amyloid $(\mathrm{A} \beta)$ is one of the main features of $\mathrm{AD}$. The formation of hyperphosphorylated Tau (microtubuleassociated protein) in the neurons is also linked with $\mathrm{AD}$. PD is a movement disorder which is characterized by abnormal aggregation of $\alpha$-synuclein protein in the neurons [33]. Similarly, abnormal long polyglutamine (PolyQ) may lead to Huntington's disease [34].

Another important brain disorder related to CNS inflammation and characterized by learning and social disabilities with no definite pathogenesis is known as autism spectrum disorder (ASD). Multiple biochemical and molecular features could be observed for the neurodegeneration in the brain of ASD [35, 36] including oxidative stress [37, 38], activated astrocytes and microglia [39, 40], neuronal loss [35, 40], elevated levels of 8-oxo-guanosine [41], and development of proinflammatory cytokines $[40,42]$.

Children with ASD tend to behave differently under stress or when exposed to certain foods, showing skin allergies [43]. Neurotensin with release of corticotrophin-releasing hormone under stressful conditions stimulates the microglia and mast cells leading to neurotoxicity and focal brain inflammation. In case of ASD, various pathological states could be observed but not in all ASD children including allergic symptoms, increased anti-brain protein autoantibodies, high anxiety, increased oxidative stress, and increased food intolerance while decreasing the levels of reduced glutathione, sulfation, and methylation [43]. Luteolin (a flavonoid) showed inhibitory effects on human mast cells that release tumor necrosis factor (TNF) [44]. Luteolin such as epigallocatechin gallate inhibits [45] mammalian target of rapamycin (mTOR) which stimulates the mast cells and microglia proliferation $[46,47]$ leading to the retardation of the release of TNF which could initiate apoptosis, necroptosis, and/or inflammation in the biological system. Various important biological actions of luteolin are illustrated (Figure 2) which may be helpful in children of ASD.

\section{Blood Brain Barrier (BBB)}

The blood brain barrier (BBB) is responsible for the regulation of small molecules (solutes) between the CNS and the blood circulation. Three different kinds of barriers could be observed where the central nervous system and blood interact; arachnoid barrier, blood-cerebrospinal fluid (CSF) barrier and the $\mathrm{BBB}$. The neurons in the CNS signal by sending action potentials through which neurons interact in the biological system. The BBB had tight junctions between cells responsible for the reduction of flux mechanism through the paracellular pathway and intercellular cleft (physical barrier) and mediation of solute flux mechanisms (transport barrier) as well as enzyme metabolizing molecules (metabolic barrier). Moreover, the functions of barriers are equally operated in physiological and pathological states of BBB [48]. The tight junctions present between the astrocytes (part of the BBB) are composed of claudin and occludin proteins. Damage in these proteins or tight junctions can lead to the loss of BBB integrity with functional barrier loss $[49,50]$. Various drugs, either synthetic or natural, may have their own mode of action but drugs used in the treatment of brain disorders have to cross the BBB to gain entry into the CNS, since structural and/or functional dysfunction in the BBB leads to inflammatory changes in the tissue such as movement of immune mediators in the brain, further contributing to the neurodegenerative process [51].

\section{Inhibition of Cholinesterase Activity}

Stimulating acetylcholine release in the brain region is one of the ways used in the treatment of neurodegenerative disorder such as $\mathrm{AD}$ that can further contribute to dementia and decline in higher cognitive function [52]. The pathological state of CNS particularly related to $\mathrm{AD}$ is characterized by neurofibrillary tangles, derangement of neurotransmitters in the neurons and synaptic cleft, and $\beta$-amyloids plaques all of which are related inflammatory mechanisms [53-55]. Both acetylcholinesterase (AChE) and butyrylcholinesterase (BChE) are responsible for the breakdown of acetylcholine in the synaptic region and low levels of acetylcholine has been found to be related to age-related disorders that leads to loss of cognitive ability $[18,56]$.

Reactive oxygen species (ROS) developed as a result of oxidative stress in the biological system can contribute to damage of biological macromolecules and as a result pathological state at cellular level can become more evident. Such pathogenic state plays a crucial role in the aging process [57]. Cholinesterase inhibitors are not commonly used in allopathic and current treatments do not lead to sufficient production of acetylcholine to help in the management of AD [18]. The research in the field of phytochemicals has developed into investigation of natural compounds responsible for antioxidative (Table 2) and antiaging properties that can also be useful for neurodegenerative disorders $[18,58]$. It is important to stimulate the cholinergic receptors in the CNS or enhance the prolonged production of acetylcholine in the synaptic cleft with the help of such active constituents that could retard the activities of AChE and $\mathrm{BChE}$ in the neuronal system. When the inhibition of enzyme activities is $60 \%$ or more by the plants extracts, compounds 


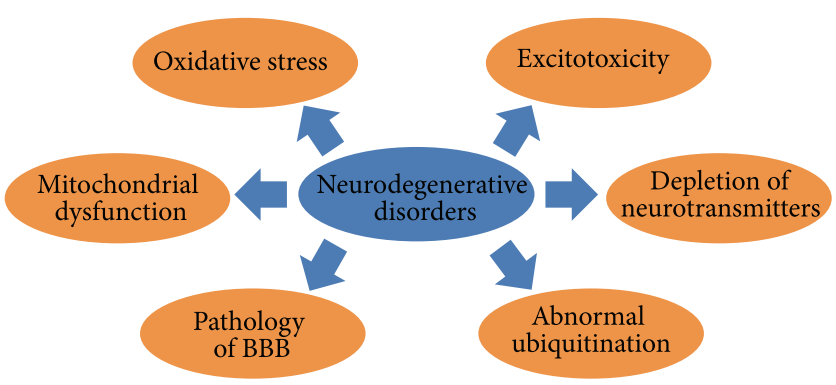

FIGURE 1: Various biological mechanisms contributing to neurodegenerative disorders.

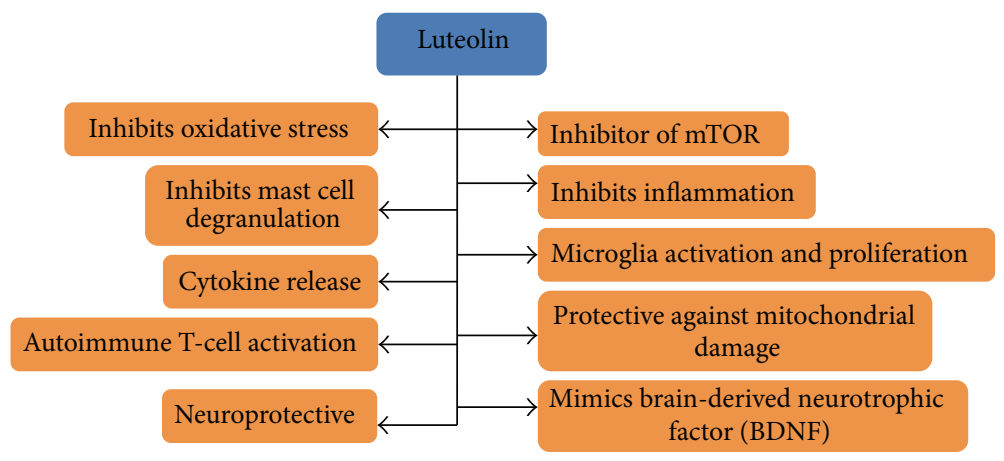

FIGURE 2: Luteolin (flavonoid) responsible for multiple biological functions.

are generally considered as strong inhibitors (Table 3) [59].

\section{Anti-Inflammatory and Antioxidative Activites}

Various medicinal plants have anti-inflammatory activities by inhibiting cyclooxygenase-1 (COX-1) that surrounds amyloids plaque in microglia. The accumulation of COX1 enzyme in microglia in $\mathrm{AD}$ patients may be responsible for the local increase in oxidative stress and prostaglandin synthesis [10]. Ferula assafoetida, Syzygium aromaticum, and Zingiber officinalis have previously been reported to have activity against COX-1 enzyme [10]. F. assafoetida has previously been used as memory enhancer, antibacterial, antispasmodic, and antihelminthic in traditional medicines. $Z$. officinalis showed not only anti-COX-1 activity but also free radical scavenging activity that may be contributed to the presence of important phytochemicals such as gingerols and shogaols [10].

Sinapic acid (Brassicaceae) shows anti-inflammatory activity and can act as a neuroprotective agent by decreasing the levels of $\mathrm{A} \beta$ and by protecting neuronal cell death [15]. On the other hand, Emblica officinalis may be used in the treatment of mental disorders and as anti-inflammatory agent [60]. Several natural polyphenols such as vitamins, flavonoids, phenolic acids, and other polyphenols including thymol, ellagic acid, and eugenol have antioxidant properties and may be used for neurodegenerative diseases as promising therapeutic agents (Tables 1 and 3).

\section{Computational Approaches towards Neurodegenerative Disorders}

With the advancements in computational fields, particularly in the field of bioinformatics, the understanding of biological system at molecular level has improved drastically. The action of enzymes with their substrates, the synthesis of proteins, degradation of various biological macromolecules, ubiquitination, and many other processes could be observed with various computational programs including in silico molecular docking strategies. The normal homeostasis including metabolic equilibrium associated with many complex biological mechanisms under the supervision of autonomic nervous system as well as prediction for pathological state and possible therapeutic suggestions.

Jeyam et al. [7] used the in silico techniques for the understanding of molecular behavior of some traditional medicines for the management of PD. The loss of dopamine is considered as prominent feature of PD. Currently, levodopa (L-Dopa) is given in the form of supplementation for the management of PD. Catecholamine-O-methyltransferase (COMT), an enzyme, is responsible for the metabolism and conversion of L-Dopa into 3-O-methyl dopa. Hence, the inhibition of COMT may be one of the important 
TABLE 1: Role of various plants and their active constituents in brain disorders.

\begin{tabular}{lcrr}
\hline Plant & Active Compounds & Disorder & References \\
\hline Adhatoda vasica & Vasicine, vasicol, vasicinol, arachidic, cerotic, linoleic and oleic acids & AD, PD & {$[6]$} \\
Ginkgo biloba & Amentoflavone & PD & {$[7]$} \\
Mandukparni & Asiaticoside & Schizophrenia & {$[8]$} \\
Panax ginseng & Ginsenoside & PD & {$[7]$} \\
Rauvolfia serpentina & Reserpine & Schizophrenia & {$[8]$} \\
Withania somnifera & Withaferin A, sitoindoside IX, physagulin D, withanoside IV, viscosalactone B & Schizophrenia & {$[8]$} \\
\hline
\end{tabular}

TABLE 2: Plants with antioxidant properties which could be applied in the therapy used in neurodegenerative diseases.

\begin{tabular}{lll}
\hline Plants & Active Compounds & References \\
\hline Abrus precatorius & Glycyrrhizin, precol, abrol, gallic acid, abrine & [9] \\
Acorus calamus & $\alpha$-asarone, $\beta$-asrone, eugenol & Vasicine, vasicol, vasicinol, arachidic, cerotic, linoleic, oleic acids \\
Adhatoda vasica & Castalagin, flavogallonic acid & {$[6]$} \\
Anogeissus leiocarpus & Emblicanins A, B, punigluconin, pedunculagin, punicafolin, ellagic acid, gallic acid & {$[9]$} \\
Emblica officinalis & Khayseneganin, luteolin, catechin \\
Entandrophragma angolense & $7 \alpha$-obacunyl acetate, cycloartane \\
Khaya senegalensis & Soysaponin I, azukisaponin V \\
Medicago sativa & Spearmint oil, $\alpha, \beta$-pinene, carvone, linalool, limonene \\
Mentha spicata & $\alpha$-pinene, 1, 8-cineole, limonene \\
Myrtus communis & Quercetin & {$[10]$} \\
Pavetta crassipes & Piperine & {$[9]$} \\
Piper nigrum & Rosmarinic acid, ferulic acid, luteolin, quercetin \\
Salvia triloba & Alkaloids, flavonoids, tannins, saponins \\
Sonchus eruca & Arjunic acid, arjunolic acid, gallic acid, ellagic acid, proanthocyanidins \\
Terminalia arjuna & Arjungenin, chebulosides, gallic acid, ellagic acid, luteolin, tannic acid, luteic acid, chebulic acid \\
Terminalia chebula & Neohecogenin, $\beta$-D-galactopyranside \\
Tribulus terrestris & Coagulin, withanolide, withaferin A \\
Withania coagulaus & Withaferin A, sitoindoside IX, physagulin D, withanoside IV, viscosalactone B \\
Withania somnifera & {$[6]$} \\
\hline
\end{tabular}

ways to treat the disorder. Considering this way of treatment, the neuroprotective phytocompounds were evaluated using in silico studies [7]. Phytochemicals such as baicalin, stigmasterol, emodin, curcumin, wogonin, and eriodictyol were found to be having binding energies of approximately $-7 \mathrm{kcal} / \mathrm{mol}$ which was similar to talcapone (synthetic drug to enhance the levodopa treatment) indicating that amentoflavone from Ginkgo biloba and ginsenoside from Panax ginseng are perceived as very good inhibitors for COMT as well as good adjuvants for L-dopa management. Kuhn and Kollman [61] studied and calculated the free energy activation of COMT considering the molecular dynamics of this enzyme. Moreover, Lee and Kim [62] investigated human COMT for designing anti-PD drug by using the ligand docking and comparative homology modeling.

Ayurveda medication has been evaluated for schizophrenia using in silico techniques [8]. Schizophrenia is associated with misbalancing of various chemicals of the brain involving the glutamate and dopamine. Studies on schizophrenia indicated that patients have abnormalities in brain structure such as decreased size of certain brain regions, enlargement of fluid-filled cavities, and less metabolic activities. Moreover, patients have delusions and hallucinations. From the Indian medication, three plants (Rauvolfia serpentina, Withania somnifera, and Mandukparni) were selected for the investigation of their role in the management of schizophrenia by using the tools of bioinformatics. The active molecules from these plants were docked with RGS-4 protein (regulator for $G$ protein signaling-4) considered to be responsible for schizophrenia. The docking of RGS-4 protein with the combinations of reserpine, withanolide, and asiaticoside from Rauvolfia serpentina, Withania somnifera, and Mandukparni, respectively, showed that such combination therapy could be helpful in the management of schizophrenia [8].

\section{Conclusion}

In future, phytochemicals could be used as promising therapeutic agents for neurodegenerative disorders due to their anti-inflammatory and antioxidative as well as anticholinesterase activities. The neurodegenerative disorders 
TABLE 3: List of plants having antioxidative and anticholinesterase activity.

\begin{tabular}{|c|c|c|c|}
\hline Plant & Active compounds & Properties & References \\
\hline Acorus calamus & $\alpha$-asarone, $\beta$-asrone, eugenol & Antioxidative, anticholinesterase & {$[13]$} \\
\hline Adhatoda vasica & $\begin{array}{l}\text { Vasicine, vasicol, vasicinol, arachidic, cerotic, } \\
\text { linoleic, oleic acids }\end{array}$ & Anticholinesterase & {$[10]$} \\
\hline Bacopa monnieri & $\begin{array}{l}\text { Bacoside, brahmin, herpestine, d-mannitol, } \\
\text { luteolin, apigenin }\end{array}$ & Anticholinesterase & {$[14]$} \\
\hline Brassica species & Brassicasterol, sinapic acid, sinapine & $\begin{array}{l}\text { Anti-inflammatory, neuroprotective, } \\
\text { anticholinesterase }\end{array}$ & {$[15-17]$} \\
\hline Buddleja salviifolia & Phenols, flavonoids, proanthocyanidins & Antioxidative, anticholinesterase & {$[18]$} \\
\hline Chamaecrista mimosoides & Phenols, flavonoids, proanthocyanidins & Antioxidative, anticholinesterase & {$[18]$} \\
\hline Corydalis species & & AChE inhibition & {$[19]$} \\
\hline Corydalis ternate & Protopine & Anticholinesterase, antiamnesic & [20] \\
\hline Cymbopogon schoenanthus & Piperitone, 2-carene & $\begin{array}{l}\text { Antioxidative, anticholinesterase, } \\
\text { antimicrobial }\end{array}$ & {$[21]$} \\
\hline Ferula assafoetida & Cadinene, eremophilene & Anti-COX-1 & {$[10]$} \\
\hline Ginkgo biloba & Ginkgetin, ginkoglides-A, B & Anticholinesterase & {$[14]$} \\
\hline Myricaria elegans & Crude extract & Anticholinesterase, antilipooxygenase & {$[22]$} \\
\hline Nardostachys jatamansi & $\begin{array}{l}\text { Angelicin, } \beta \text {-eudesmol, calarene, calarenol, } \\
\text { elemol, nardol, oroselol }\end{array}$ & Antioxidative, anticholinesterase & {$[13]$} \\
\hline Origanum ehrenbergii & Carvacrol, thymol & Antioxidative, anti-inflammatory & {$[23]$} \\
\hline Origanum syriacum & Carvacrol, thymol & $\begin{array}{l}\text { Antioxidative, anti-inflammatory, } \\
\text { anticholinesterase }\end{array}$ & {$[23]$} \\
\hline Peganum harmala & Norharmane, harmine, harmalol & Anticholinesterase & {$[10]$} \\
\hline Piper nigrum & Piperine & Antioxidative, anticholinesterase & {$[11]$} \\
\hline Ptychopetalum olacoides & Lupeol, $\alpha, \beta$-pinene & Anticholinesterase & [24] \\
\hline Salvia lavandulaefolia & Essential oil, terpenes & Anticholinesterase & [25] \\
\hline Salvia miltiorrhiza & Diterpenoid & Anticholinesterase & {$[26]$} \\
\hline Salvia miltiorrhiza & Terpenes, tanshinones & Anticholinesterase & {$[26,27]$} \\
\hline Salvia officinalis & Polyphenols & Antioxidative, anticholinesterase & {$[28,29]$} \\
\hline Salvia plebeian & Essential oil & Antioxidative & {$[30]$} \\
\hline Salvia tiliifolia & Phenols, flavonoids, proanthocyanidins & Antioxidative, inhibition of cholinesterase & {$[18]$} \\
\hline Salvia triloba & Rosmarinic acid, ferulic acid, luteolin, quercetin & Antioxidative, anticholinesterase & {$[11]$} \\
\hline Schotia brachypetala (root) & Phenols, flavonoids, proanthocyanidins & Antioxidative, anticholinesterase & {$[18]$} \\
\hline Schotia brachypetala (bark) & Phenols, flavonoids, proanthocyanidins & Antioxidative, anticholinesterase & {$[18]$} \\
\hline Syzygium aromaticum & Eugenol, trans- $\beta$-caryophyllene, $\alpha$-humulene & Anti-COX-1 & {$[10]$} \\
\hline Tabernaemontana divaricata & Voafinidine, lupeol, $\alpha$-amyrin, $\beta$-sitosterol & Anticholinesterase & {$[31]$} \\
\hline Terminalia chebula & Penta-O-galloyl- $\beta$-D-glucose & Anticholinesterase & {$[32]$} \\
\hline Zingiber officinale & Gingerol, shogaol, zingerone & Anti-COX-1 & {$[10]$} \\
\hline
\end{tabular}

such as $\mathrm{AD}, \mathrm{PD}$, Huntington's, and others share common features at cellular and subcellular levels as well as sharing mostly common molecular signaling pathways that may lead to apoptosis, necroptosis, and inflammation. Overall phytochemicals provide promising alternatives to current therapies for neurodegenerative disorders.

\section{Conflict of Interests}

The authors declare that they have no conflict of interests.

\section{References}

[1] E. Wong and A. M. Cuervo, "Autophagy gone awry in neurodegenerative diseases," Nature Neuroscience, vol. 13, no. 7, pp. 805811, 2010.

[2] A. Ciechanover, "The ubiquitin proteolytic system: from a vague idea, through basic mechanisms, and onto human diseases and drug targeting," Neurology, vol. 66, no. 2, pp. 7-19, 2006.

[3] O. I. Aruoma, T. Bahorun, and L.-S. Jen, "Neuroprotection by bioactive components in medicinal and food plant extracts," Mutation Research, vol. 544, no. 2-3, pp. 203-215, 2003. 
[4] P. Jenner and C. W. Olanow, "Understanding cell death in Parkinson's disease," Annals of Neurology, vol. 3, no. 1, pp. 7284, 1998.

[5] C. Behl, "Alzheimer's disease and oxidative stress: implications for novel therapeutic approaches," Progress in Neurobiology, vol. 57, no. 3, pp. 301-323, 1999.

[6] I. Hussain, N. Khan, H. Khan et al., "Screening of anti-oxidant activities of selected medicinal plants," World Applied Sciences Journal, vol. 11, no. 3, pp. 338-340, 2010.

[7] M. Jeyam, G. R. R. Karthika, V. Poornima, and M. Sharanya, "Molecular understanding and in silico validation of traditional medicines for Parkinson's disease," Asian Journal of Pharmaceutical and Clinical Research, vol. 5, no. 4, pp. 125-128, 2012.

[8] P. Bagchi, A. Kar, and C. S. Vinobha, "Establishing an in-silico ayurvedic medication towards treatment of Schizophrenia," International Journal of Systems Biology, vol. 1, no. 2, pp. 46-50, 2009.

[9] O. Olutayo, I. Doyinsola, O. Simon, O. Abayomi, and S. Thomas, "Phytochemical and antioxidant properties of some Nigerian medicinal plants," American Journal of Scientific and Industrial Research, vol. 4, no. 3, pp. 328-332, 2011.

[10] S. K. Ali, A. R. Hamed, M. M. Soltan et al., "In-vitro evaluation of selected Egyptian traditional herbal medicines for treatment of Alzheimer disease," BMC Complementary and Alternative Medicine, vol. 13, article 121, 2013.

[11] K. Mahdy, O. Shaker, H. Wafay, Y. Nassar, H. Hassan, and A. Hussein, "Effect of some medicinal plant extracts on the oxidative stress status in Alzheimer's disease induced in rats," European Review for Medical and Pharmacological Sciences, vol. 16, no. 3, pp. 31-42, 2012.

[12] R. Ullah, J. A. Khader, N. M. AbdEIslam et al., "Antioxidant activity of different crude fractions of Sonchus eruca," Life Science Journal, vol. 10, no. 2, pp. 835-837, 2013.

[13] F. Ahmed, N. S. Chandra, A. Urooj, and K. S. Rangappa, “In vitro antioxidant and anti-cholinesterase activity of Acorus calamus and Nardostachys jatamansi rhizomes," Journal of Pharmacy Research, vol. 2, no. 5, pp. 830-833, 2009.

[14] A. Das, G. Shanker, C. Nath, R. Pal, S. Singh, and H. K. Singh, "A comparative study in rodents of standardized extracts of Bacopa monniera and Ginkgo biloba anti-cholinesterase and cognitive enhancing activities," Pharmacology Biochemistry and Behavior, vol. 73, no. 4, pp. 893-900, 2002.

[15] H. E. Lee, D. H. Kim, S. J. Park et al., "Neuroprotective effect of sinapic acid in a mouse model of amyloid beta(1-42) proteininduced Alzheimer's disease," Pharmacology Biochemistry and Behavior, vol. 103, no. 2, pp. 260-266, 2012.

[16] T. Vanmierlo, J. Popp, H. Kölsch et al., "The plant sterol brassicasterol as additional CSF biomarker in Alzheimer's disease," Acta Psychiatrica Scandinavica, vol. 124, no. 3, pp. 184-192, 2011.

[17] H. K. Dong, H. Y. Byung, Y.-W. Kim et al., "The seed extract of Cassia obtusifolia ameliorates learning and memory impairments induced by scopolamine or transient cerebral hypoperfusion in mice," Journal of Pharmacological Sciences, vol. 105, no. 1, pp. 82-93, 2007.

[18] E. A. Adewusi, N. Moodley, and V. Steenkamp, "Antioxidant and acetylcholinesterase inhibitory activity of selected southern African medicinal plants," South African Journal of Botany, vol. 77, no. 3, pp. 638-644, 2011.

[19] A. Adsersen, B. Gauguin, L. Gudiksen, and A. K. Jäger, "Screening of plants used in Danish folk medicine to treat memory dysfunction for acetylcholinesterase inhibitory activity," Journal of Ethnopharmacology, vol. 104, no. 3, pp. 418-422, 2006.
[20] S. R. Kim, S. Y. Hwang, Y. P. Jang et al., "Protopine from Corydalis ternata has anticholinesterase and antiamnesic activities," Planta Medica, vol. 65, no. 3, pp. 218-221, 1999.

[21] A. Khadri, M. Neffati, S. Smiti et al., "Antioxidant, antiacetylcholinesterase and antimicrobial activities of Cymbopogon schoenanthus L. Spreng, (lemon grass) from Tunisia," LWT Food Science and Technology, vol. 43, no. 2, pp. 331-336, 2010.

[22] W. Ahmad, B. Ahmad, M. Ahmad, Z. Iqbal, M. Nisar, and M. Ahmad, "In vitro inhibition of acetylcholinesterase, butyrylcholinesterase and lipoxygenase by crude extract of Myriacaria elegans Royle," Journal of Biological Sciences, vol. 3, no. 11, pp. 1046-1049, 2003.

[23] M. R. Loizzo, F. Menichini, F. Conforti et al., "Chemical analysis, antioxidant, antiinflammatory and anticholinesterase activities of Origanum ehrenbergii Boiss and Origanum syriacum L. essential oils," Food Chemistry, vol. 117, no. 1, pp. 174-180, 2009.

[24] I. R. Siqueira, C. Fochesatto, A. L. da Silva et al., "Ptychopetalum olacoides, a traditional Amazonian "nerve tonic", possesses anticholinesterase activity," Pharmacology Biochemistry and Behavior, vol. 75, no. 3, pp. 645-650, 2003.

[25] N. S. L. Perry, P. J. Houghton, A. Theobald, P. Jenner, and E. K. Perry, "In vitro inhibition of human erythrocyte acetylcholinesterase by Salvia lavandulaefolia essential oil and constituent terpenes," Journal of Pharmacy and Pharmacology, vol. 52, no. 7, pp. 895-902, 2000.

[26] Y. Ren, P. J. Houghton, R. C. Hider, and M.-J. R. Howes, "Novel diterpenoid acetylcholinesterase inhibitors from Salvia miltiorhiza," Planta Medica, vol. 70, no. 3, pp. 201-204, 2004.

[27] I. Orhan and M. Aslan, "Appraisal of scopolamine-induced antiamnesic effect in mice and in vitro antiacetylcholinesterase and antioxidant activities of some traditionally used Lamiaceae plants," Journal of Ethnopharmacology, vol. 122, no. 2, pp. 327332, 2009.

[28] Y. Lu and L. Yeap Foo, "Antioxidant activities of polyphenols from sage (Salvia officinalis)," Food Chemistry, vol. 75, no. 2, pp. 197-202, 2001.

[29] I. Orhan, M. Kartal, Q. Naz et al., "Antioxidant and anticholinesterase evaluation of selected Turkish Salvia species," Food Chemistry, vol. 103, no. 4, pp. 1247-1254, 2007.

[30] X. C. Weng and W. Wang, "Antioxidant activity of compounds isolated from Salvia plebeia," Food Chemistry, vol. 71, no. 4, pp. 489-493, 2000.

[31] S. Chattipakorn, A. Pongpanparadorn, W. Pratchayasakul, A. Pongchaidacha, K. Ingkaninan, and N. Chattipakorn, "Tabernaemontana divaricata extract inhibits neuronal acetylcholinesterase activity in rats," Journal of Ethnopharmacology, vol. 110, no. 1, pp. 61-68, 2007.

[32] S. Sancheti, S. Sancheti, B.-H. Um, and S.-Y. Seo, "1,2,3,4,6penta-O-galloyl- $\beta$-d-glucose: a cholinesterase inhibitor from Terminalia chebula," South African Journal of Botany, vol. 76, no. 2, pp. 285-288, 2010.

[33] V. M.-Y. Lee and J. Q. Trojanowski, "Mechanisms of Parkinson's disease linked to pathological alpha-synuclein: new targets for drug discovery," Neuron, vol. 52, no. 1, pp. 33-38, 2006.

[34] G. Bates, "Huntingtin aggregation and toxicity in Huntington's disease," The Lancet, vol. 361, no. 9369, pp. 1642-1644, 2003.

[35] E. Courchesne, K. Pierce, C. M. Schumann et al., "Mapping early brain development in autism," Neuron, vol. 56, no. 2, pp. 399413, 2007. 
[36] J. K. Kern, D. A. Geier, L. K. Sykes, and M. R. Geier, "Evidence of neurodegeneration in autism spectrum disorder," Translational Neurodegeneration, vol. 2, article 17, 2013.

[37] A. Chauhan, F. Gu, M. M. Essa et al., "Brain region-specific deficit in mitochondrial electron transport chain complexes in children with autism," Journal of Neurochemistry, vol. 117, no. 2, pp. 209-220, 2011.

[38] A. Chauhan, T. Audhya, and V. Chauhan, "Brain regionspecific glutathione redox imbalance in autism," Neurochemical Research, vol. 37, pp. 1681-1689, 2012.

[39] J. T. Morgan, G. Chana, C. A. Pardo et al., "Microglial activation and increased microglial density observed in the dorsolateral prefrontal cortex in autism," Biological Psychiatry, vol. 68, no. 4 , pp. 368-376, 2010.

[40] D. L. Vargas, C. Nascimbene, C. Krishnan, A. W. Zimmerman, and C. A. Pardo, "Neuroglial activation and neuroinflammation in the brain of patients with autism," Annals of Neurology, vol. 57, no. 1, pp. 67-81, 2005.

[41] E. M. Sajdel-Sulkowska, M. Xu, and N. Koibuchi, "Increase in cerebellar neurotrophin-3 and oxidative stress markers in autism," Cerebellum, vol. 8, no. 3, pp. 366-372, 2009.

[42] M. G. Chez, T. Dowling, P. B. Patel, P. Khanna, and M. Kominsky, "Elevation of tumor necrosis factor-alpha in cerebrospinal fluid of autistic children," Pediatric Neurology, vol. 36, no. 6, pp. 361-365, 2007.

[43] T. C. Theoharides, S. Asadi, and A. B. Patel, "Focal brain inflammation and autism," Journal of Neuroinflammation, vol. 10, p. 46, 2013.

[44] E. Middleton Jr., C. Kandaswami, and T. C. Theoharides, “The effects of plant flavonoids on mammalian cells: implications for inflammation, heart disease, and cancer," Pharmacological Reviews, vol. 52, no. 4, pp. 673-751, 2000.

[45] G. S. van Aller, J. D. Carson, W. Tang et al., "Epigallocatechin gallate (EGCG), a major component of green tea, is a dual phosphoinositide-3-kinase/mTOR inhibitor," Biochemical and Biophysical Research Communications, vol. 406, no. 2, pp. 194199, 2011.

[46] D. Smrž, M.-S. Kim, S. Zhang et al., "MTORC1 and mTORC2 differentially regulate homeostasis of neoplastic and nonneoplastic human mast cells," Blood, vol. 118, no. 26, pp. 68036813, 2011.

[47] Y. C. Shang, Z. Z. Chong, S. Wang, and K. Maiese, "Erythropoietin and Wntl govern pathways of mTOR, Apaf-1, and XIAP in inflammatory microglia," Current Neurovascular Research, vol. 8, no. 4, pp. 270-285, 2011.

[48] N. J. Abbott, L. Rönnbäck, and E. Hansson, "Astrocyteendothelial interactions at the blood brain barrier," Nature Reviews Neuroscience, vol. 7, pp. 41-53, 2006.

[49] N. J. Abbott, A. A. K. Patabendige, D. E. M. Dolman, S. R. Yusof, and D. J. Begley, "Structure and function of the blood-brain barrier," Neurobiology of Disease, vol. 37, no. 1, pp. 13-25, 2010.

[50] H. Wolburg, K. Wolburg-Buchholz, J. Kraus et al., "Localization of claudin-3 in tight junctions of the blood-brain barrier is selectively lost during experimental autoimmune encephalomyelitis and human glioblastoma multiforme," Acta Neuropathologica, vol. 105, no. 6, pp. 586-592, 2003.

[51] A. M. Palmer, "The role of the blood brain barrier in neurodegenerative disorders and their treatment," Journal of Alzheimer's Disease, vol. 24, no. 4, pp. 643-656, 2011.

[52] D. Dhingra, M. Parle, and S. K. Kulkarni, "Genetic basis of Alzheimer's disease," Indian Journal of Pharmaceutical Sciences, vol. 67, no. 4, pp. 409-413, 2005.
[53] E. Bossy-Wetzel, R. Schwarzenbacher, and S. A. Lipton, "Molecular pathways to neurodegeneration," Nature Medicine, vol. 10, pp. 2-9, 2004.

[54] D. J. Selkoe, "Alzheimer's disease: genes, proteins, and therapy," Physiological Reviews, vol. 81, no. 2, pp. 741-766, 2001.

[55] M. Rasool, A. Malik, A. Qazi et al., "Current view from Alzheimer disease to type 2 diabetes mellitus," CNS \& Neurological Disorders-Drug Targets, vol. 13, no. 3, 2013.

[56] C. C. Felder, F. P. Bymaster, J. Ward, and N. DeLapp, “Therapeutic opportunities for muscarinic receptors in the central nervous system," Journal of Medicinal Chemistry, vol. 43, no. 23, pp. 4333-4353, 2000.

[57] X. Zhu, A. K. Raina, H.-G. Lee, G. Casadesus, M. A. Smith, and G. Perry, "Oxidative stress signalling in Alzheimer's disease," Brain Research, vol. 1000, no. 1-2, pp. 32-39, 2004.

[58] D. Fusco, G. Colloca, M. R. Lo Monaco, and M. Cesari, "Effects of antioxidant supplementation on the aging process," Clinical Interventions in Aging, vol. 2, no. 3, pp. 377-387, 2007.

[59] R. A. Khan, I. A. Bukhari, S. A. Nawaz, and M. I. Choudhary, "Acetylcholinesterase and butyrylcholinesterase inhibitory potential of some Pakistani medicinal plants," Journal of Basic and Applied Sciences, vol. 2, pp. 7-10, 2006.

[60] K. R. Anilakumar, N. S. Nagaraj, and K. Santhanam, "Reduction of hexachlorocyclohexane-induced oxidative stress and cytotoxicity in rat liver by emblica officinalis gaertn," Indian Journal of Experimental Biology, vol. 45, no. 5, pp. 450-454, 2007.

[61] B. Kuhn and P. A. Kollman, "QM-FE and molecular dynamics calculations on catechol O-methyltransferase: free energy of activation in the enzyme and in aqueous solution and regioselectivity of the enzyme-catalyzed reaction," Journal of the American Chemical Society, vol. 122, no. 11, pp. 2586-2596, 2000.

[62] J.-Y. Lee and Y. Kim, "Comparative homology modeling and ligand docking study of human catechol-O-methyltransferase for antiparkinson drug design," Bulletin of the Korean Chemical Society, vol. 26, no. 11, pp. 379-385, 2005. 


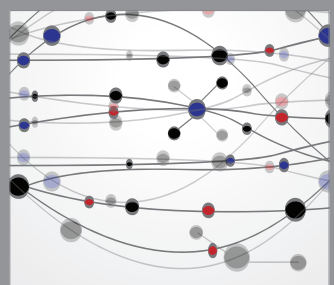

The Scientific World Journal
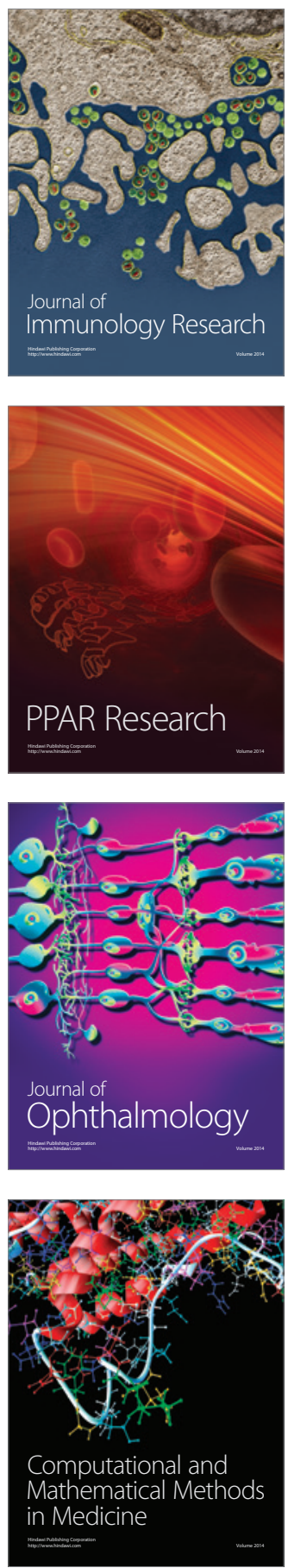

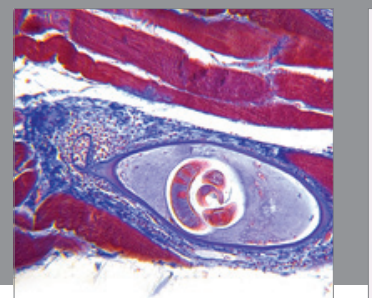

Gastroenterology

Research and Practice
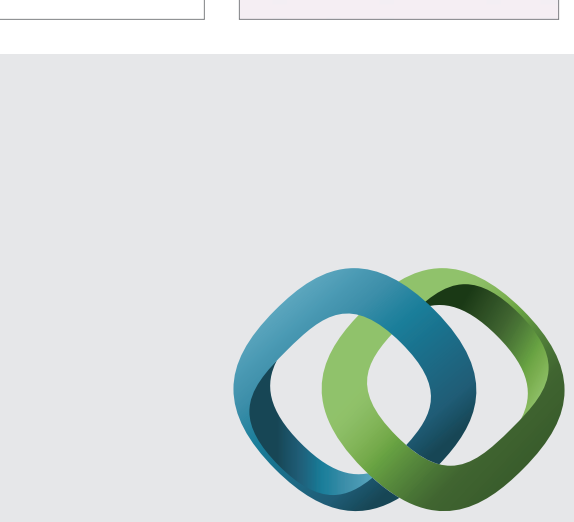

\section{Hindawi}

Submit your manuscripts at

http://www.hindawi.com
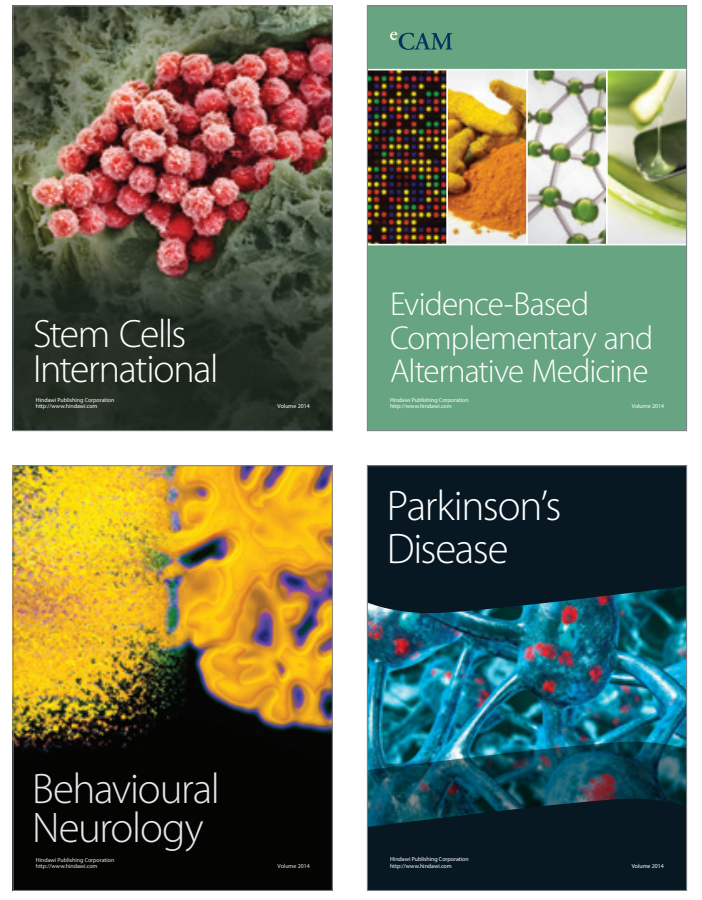
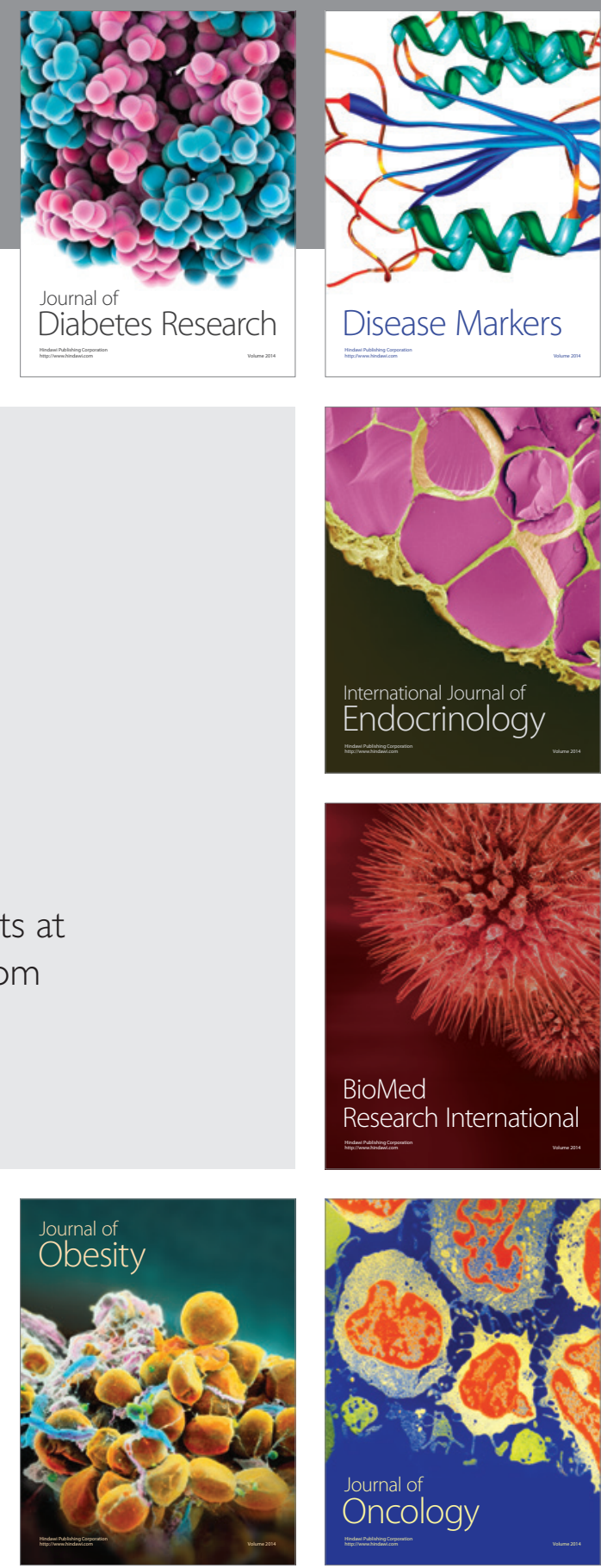

Disease Markers
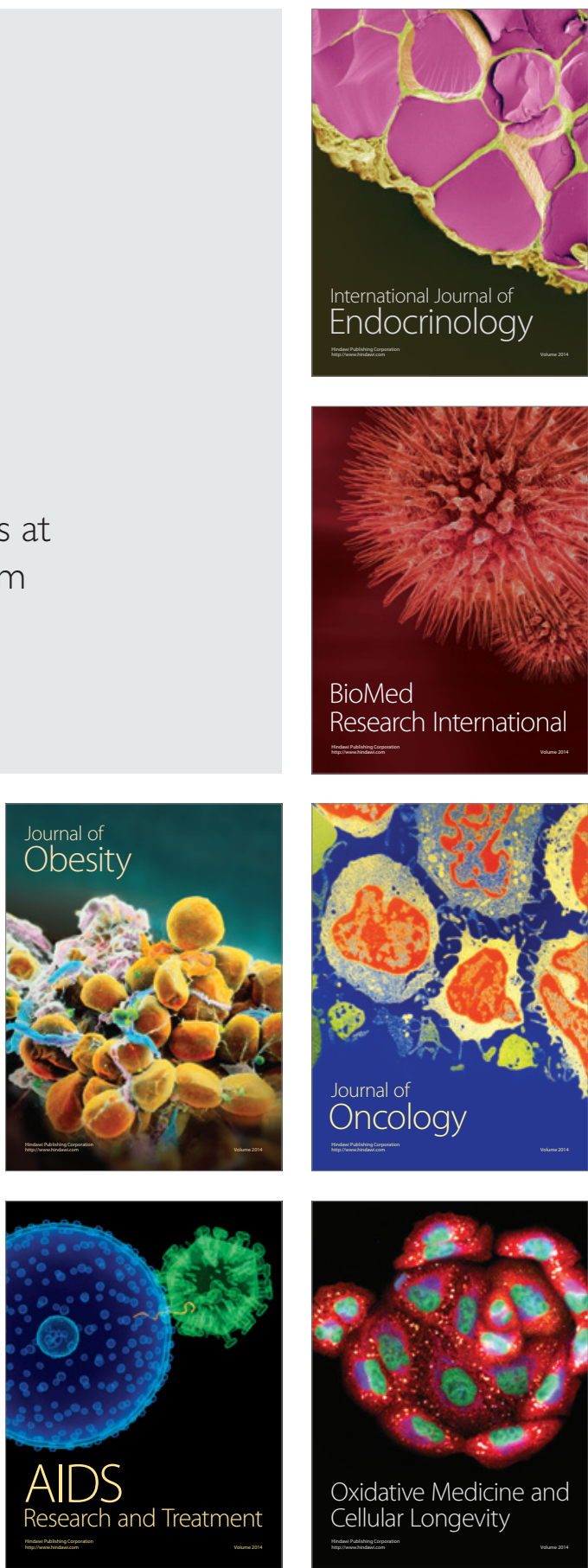